\title{
Economic Challenges and Opportunities after the Revolution in Tunisia: Inflation and Exchange Rate
}

\section{Loukil S*}

Department of Management, Sfax University, Tunisia

\begin{abstract}
This paper investigates the dynamic links between the exchange rate and the inflation in Tunisia, using annual data during the period 1984-2016. First, we implement unit root analysis to test the stationary. The study makes use of both primary and secondary data and VAR Granger Causality/Block Erogeneity Wald Tests were adopted as the estimation techniques. Granger causality results reveal that there is a unidirectional causal link between the inflation and exchange running from the inflation to the exchange rate and that the exchange rate has no impact on inflation. This study provides some implications regarding potential constraints on monetary policy. A policy of inflation targeting, as an alternative monetary policy, combined with a compatible regime of flexible exchange rates could provide a solution to this dilemma.
\end{abstract}

Keywords: Exchange rate; Economy; Financial system; Markets; Telecommunications; Monetary policy; Imported products

\section{Introduction}

The underlying root causes of financial and macroeconomic imbalances lie not only in disequilibrium in current account balances, but also in financial recession that has shaken some Arab world countries as a result to political events, The January 2011 revolution marked the beginning of a historical era for Tunisia. It liberates the economy from stifling governance inefficiencies. Tunisia has achieved in advances at the political level with the consensual adoption of a new constitution and the emergence of a very dynamic civil society. However, this political and social post-revolution instability and a variety of external shock especially the war in Libya affected Tunisian economy which has led to financial crises. Moreover, the local capital market is small and banks' access to external funding is restricted and concentrated primarily on Tunisian expatriate deposits or long-term loans from multilateral lending institutions. The African's Development Bank Group report in 2012 suggests that structural challenges are needed to move up the value chain through the structural shift of the manufacturing sector and the liberalization of the domestic private sector from the dual economy.

After January 2011, date of the Tunisian revolution, the flagrant depreciation of the dinar impeded the different policies of central banks and threatens edits credibility (inflation targeting ${ }^{1}$ as monetary policy) [1]. To fight against economic destabilization, central banks attempted to implement reforms and new policies in order to establish a stable, efficient and reliable financial system. According to the International Monetary Fund this will first require supporting the economic recovery in the short term with an investment-oriented fiscal expansion while preserving macroeconomic and financial stability against a difficult external environment and a still-volatile political and social domestic situation. Monetary and financial sector policies should aim at containing inflation, preserving foreign reserves, and strengthening the banking sector. In fact, that central bank credibility, which was badly compromised after the crash of classical gold standard around 1914 , has been enhanced in recent decades because of the adoption of inflation targeting.

${ }^{1}$ According to Mishkin (1999) an IT regime includes the following five elements:(1) public announcement of medium-term numerical targets for inflation; (2) an institutional commitment to price stability as the primary, long-run goal of monetary policy and to achievement of the inflation goal; (3) an information inclusive strategy, with a reduced role for intermediate targets such as money growth.
In flexible regime, inflation cannot be easily controlled by monetary authorities in contrast to hard fixers. There may also be a lag time between policy and inflation outcomes. Therefore, IT does not provide immediate signals of monetary policy to the households or the markets about the stance [2].

But, in Tunisia, the de facto trend towards more closely directed regimes has taken place without a declared the de jure change in exchange rate policies. The 1990s were marked by a certain stability of the financial and economic environment and the Central Bank of Tunisia (CBT) adjust the nominal effective exchange ${ }^{2}$ (NEER) from time to time to compensate for the inflation gap compared to Tunisia's commercial partners [3].

The African Development Bank Group suggest that structural challenges are needed to moving up the value chain through structural shift of the manufacturing sector and the liberalization of the domestic private sector from the dual economy. However, exchange rates and capital accounts are still under the strict control of the Central Bank, even though exceptions are accorded to export-related activities. The public sector dominates all the strategic sectors in the economy (e.g., energy, transport, telecommunications, pharmacy, collection and trade of basic food, etc.) and basic commodities prices are controlled by the government (which represents one third of the CPI). Therefore, it is crucial to assess the response of domestic prices to the exchange rate pass-through, given its important implications for monetary policy [4]. The pass-through measures the effect of a nominal exchange rate change on prices across fluctuations in the prices of imported

${ }^{2}$ Accordingly the increased transparency of the monetary policy strategy through communication with the public and the markets about the plans and objectives of monetary policymakers; and increased accountability of the central bank for attaining its inflation objectives.

*Corresponding author: Loukil S, Professor, Department of Management, Sfax University, Tunisia, Tel: +216 74242 951; E-mail: saharloukil@windowslive.com

Received June 13, 2017; Accepted September 19, 2017; Published September 26, 2017

Citation: Loukil S (2017) Economic Challenges and Opportunities after the Revolution in Tunisia: Inflation and Exchange Rate. J Glob Econ 5: 260. doi: 10.4172/2375-4389.1000260

Copyright: (c) 2017 Loukil S. This is an open-access article distributed under the terms of the Creative Commons Attribution License, which permits unrestricted use, distribution, and reproduction in any medium, provided the original author and source are credited. 
products $^{3}$. The total exchange rate pass-through ${ }^{4}$ in Tunisia is about $20 \%$ after the revolution. Specifically, $10 \%$ of pass-through on the administered prices, which contradicts the prevailing theory that admits the inexistence of pass-through for administered prices [5].

Several researchers investigated in the relationship between exchange rate and inflation. The aim of this paper is to answer the question: What is the relationship between inflation and exchange rate? Whether there is a causal relationship duplex or unidirectional relationship between them? In this regard, the study of the relationship between inflation and exchange rate over a period of 32 years (19842016) are examined from FMI data base [6]. Next, in the second section we started by clarifying the cartography of economic repercussions of the global financial crisis combined transition factors associated with the post-revolutionary period on Tunisian monetary policy in term of inflation and exchange rate. In the third section, details of the methodological procedure are explained. Result of the causality analysis is given in the fourth section. The paper concludes in the fifth section.

\section{The Financial and Economic Context of Tunisia}

The principal mission of central bank is to maintain general price stability. For this purpose, it is particularly responsible for overseeing the monetary policy and preserves the stability and security of the financial system. In Tunisia, the monetary policy has been supportive of bank credit, which decelerated nevertheless [7]. The Central Bank of Tunisia (BCT) has launched a monetary policy aiming to preserve the value of the currency by controlling the rate of inflation at a level close to that observed in the partner countries and competitors. The role of this exchange rate policy is to defend the internal and external value of the currency and maintain its stability and support the government's economic policy.

\section{Exchange rate regime in Tunisia: perception and reality in a context of transition}

An exchange rate policy is the set of rules that determine the intervention of the monetary authorities on the exchange market and therefore the behaviour of the exchange rate. The choice of exchange rate regime and its effect on economic performance is among the most contentious issues in economic policy [8]. It depends crucially on the specificities and characteristics of the economy. In fact, the key issue in monetary policymaking is the time inconsistency problem confronting central banks.

The compensation hypothesis supposes that open trade exposes a nation to greater social and economic inequality which is the social cost of an international integration and leads to political crises. To deal with, governments respond by providing more social spending to ensure economic parity. This social compensation stimulates higher consumer spending and creates more inflation .Moreover, open trade increases importation and causes more inflation. Before revolution, as in many dictatorships, the Tunisian regime was based on the authoritarian bargain: obligatory loyalty to the regime in exchange for political

${ }^{3}$ Exchange rate affects inflation either indirectly, through the price of domestic and foreign goods and domestic demand, either directly, because the prices of imported goods included as a component of domestic goods.

${ }^{4}$ As defined by Goldberg and Knetter (1997) exchange rate pass-through is the percentage change in local currency import prices resulting from a one percent change in the exchange rate between the exporting and importing countries. Changes in import prices are, nevertheless, to some extent passed on to produce and consumer prices. stability and the distribution of jobs and other benefits. The exchange rate regime adopted is flexible [9]. But this flexibility is limited. Currently, it is a managed float without preliminary announcement of the exchange rate trajectory.

Early eighties were marked by a reduction in income transfers from Tunisian workers abroad, a decline of agricultural production due to the drought and a fall in the production of hydrocarbons as well as their price. After participating in the structural adjustment program (SAP) in 1987, the CBT for the purpose of fixing inflation has introduced the constant real effective exchange rate rule (CRECR) in order to preserve Tunisia's competitiveness. The real exchange rate depreciated sharply over the period 1986-1988. The 90s was characterized by prudent monetary and fiscal policies, with a stability of the international environment, which ensured a macroeconomic stability. Until the late 1990s, the CBT rigorously applied the CRECR rule, while combining it with strong monetary and fiscal discipline and control of capital flows. This policy results in growth for the Tunisian economy (7.32\%) and a decrease for inflation for more than 5\% in 2004 (Figure 1).

Compliance with this rule has led the Tunisian monetary authorities to periodically adjust the nominal exchange rate. At the end of 1999, the adoption of this rule was relaxed and tempered the responses of the nominal exchange rate to exogenous shocks. However, since 2000 domestic currency has been depreciated to support exportations. The total depreciation of the nominal effective exchange rate between 2000-2010 was around 30\% and between 2011-2015 it was around 15\% (inflation's increase between 2011-2015 was about 40\%).

During this period (2000-2010) the exchange rate regime for Tunisia was a "managed floating" one aiming at the equilibrium's path. Then, after the revolution 2011, the CBT follow a more flexible exchange rate policy (impure floating) after the flagrant depreciation of the dinar in order to preserve competitiveness and to avoid depleting exchange reserves. In fact, compared to the end of 2010 and through December 2011, the dinar exchange rate on the interbank market has known a down of $4.1 \%$ with respect to the US dollar and $0.8 \%$ against the euro. This monetary deterioration engenders a price increase. In fact, the inflation rate rose in May 2014 standing at 5.4\% against $5.2 \%$ in April and 5\% in $\mathrm{March}^{5}$. In 2016, Tunisia recorded an inflation rate of $4.2 \%{ }^{6}$. In comparison with the 2010 base year, inflation was $4.1 \%$ in $2015,4.8 \%$ in 2014 and $5.7 \%$ in 2013 . The national institute of statistics

\section{Exchange rate}

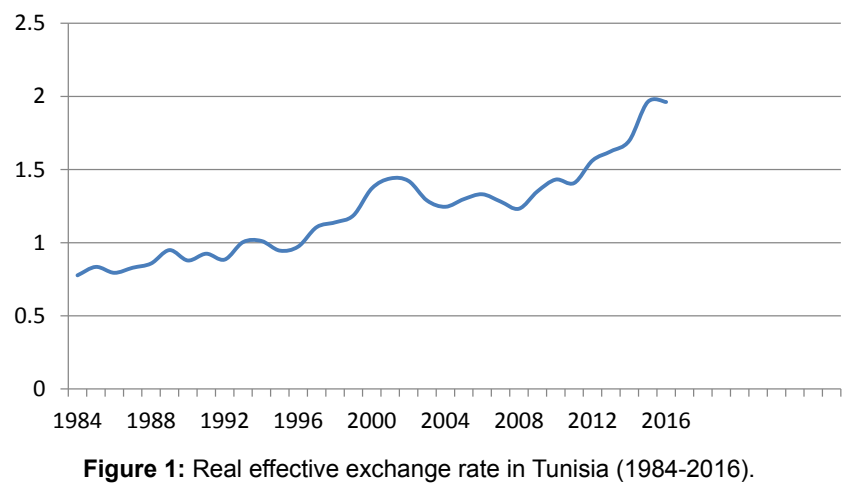

${ }^{5}$ According to the National Institute of Statistics (NIS).

${ }^{6}(3.5 \%$ in January, $3.7 \%$ in July, $3.9 \%$ in October and $4.2 \%$ in September and December, according to the Figures from the National Institute of Statistics (NSI). 
(NIS) explains this rise in the inflation rate by the price increase of the food and beverages group compared to 2015 illustrated in Figure 2.

Globally, after revolution, the interim government has managed to keep the economy from collapsing, preserve a decent level of foreign exchange reserves, and control inflation. The CBT de facto exchange rate regime differs from the CBT de jure exchange rate regimes, or officially announced, defined as what a countries government 'claims' to do. In fact, this is usually associated with a 'fear of floating' and is usually seen as intermediate exchange rate regimes.

According to the CBT report in 2015, the exchange rate is determined on the interbank market and the CBT intervenes to regulate the liquidity of the market according to its own prices, which makes it the main market maker. The exchange rate was used to protect the competitiveness of the real sector. The CBT allowed the exchange rate to depreciate in real terms because it kept in mind the rise in unit labor costs relative to those of the main partner countries and competitors. In some cases, when the national currency risks losing value, the CBT intervenes by offering the currency in order to support the dinar. This is the case of the depreciation of the national currency after the statements of the finance minister in April 2017. Then, the CBT announced the support of the Tunisian dinar by offering foreign currency to banks.

\section{The inflation regime}

The monetary policy framework is based, on the monetary aggregates, credit and on a diverse range of indicators (import prices, the output gap, core inflation...) closely linked to inflation. To ensure price stability, the CBT supervise the bank liquidity and steer interest rates in the short term through a number of instruments (required reserves, operations at the initiative of the CBT, operations at the initiative of banks). The CBT used the open Market operations in terms of bank liquidity regulation in order to contain the interest rate in a channel marked by the rate bidding (the minimum rate) and the reverse repurchase rate (the maximum rate). Therefore, "the monetary policy conducted by the CBT can be described as neutral with a certain rigidity of interest rates" 7 . The problem is that the CBT announced objectives were not always reached. These results should incite to install a dispositive which allows to a better evaluation of the authorities' initiatives.

But, the CBT makes great efforts in inflation forecasting at the short and medium terms that will serve as reference for decision making in monetary policy and a means of communication with the public by providing a means to assess and strengthen its policy, therefore, its credibility. For a more flexible context, the CBT is expected to further clarify its strategy, to explain more frequently the slippages of intermediate targets and further clarify the role of interest rates. According to the regulation, the $\mathrm{CBT}$ is required to coordinate and lend its support for the economic policy of the state. With the revolution of January 2011, it was expected that the CBT will perform its function and will be independent in decision making.

But, the governor of the central bank remains a guarantee of its autonomy. In fact, there were 12 changes on 55 years ${ }^{8}$. One must say that the term of office of the CBT's Governor is six years renewable. It seems that Tunisia is not now floating de jure and manages de facto. In what follows, we will try to understand the changes in the inflation rate

${ }^{7}$ MPRA Paper No. 61442, posted 19 January 2015 21:21 UTC.

${ }^{8}$ According to Cukierman (1992), the criteria for evaluating the degree of independence of a central bank, is 0.21 . on the last four decades. This permit us to consider that it is curbed, identifying to the rampant inflation with tendencies to the rise different of one period to the other. The period 1963-1972 is characterized by a relatively weak rhythm of inflation. Indeed, the middle rate measured by the indication of the prices to the consumption on this period maintained itself to $3.4 \%$. It is only from the first oil shock 1973 that the inflation accelerated, reaching $4.1 \%$ following the increase of the price of oil. From 1974, the authorities undertook a politics of raise by the demand to stimulate the economic growth. They increased the wages by an increase of the currency offer. But, unfortunately, this aggravated the inflation that reached 5.5\% in 1975. During the following period (1976-1978), the inflation decreased substantially and the GDP continued to grow following the enhancement of the products exported and the intervention of the General Case of Compensation (CGC). The period 1979-1982 coincided with the second oil shock, what explains the acceleration of the inflation from 1979, either $10.2 \%$ on average and per year on this period. This acceleration of the inflation was accompanied by an unfavorable economic conjuncture. But the active period of 1982-1986 is characterized by a light deceleration. The rates of inflation vary between $4.1 \%$ in 1982 and $6.3 \%$ in 1986 . The years 1984 1985 and 1986 distinguish themselves by a clean slowing of the rhythm of the inflation. This evolution could explain itself by the economic resumption that appeared during this period, with the exception of the year 1986, following the improvement of the productivity and to the compression of the interior demand what succeeded in 1986 to an unbearable deficit of the current payments (yearly Reports of the central bank (1981-1988)). To face the crisis of the balance of payments, the BCT devalued the dinar strongly, modified its monetary politics and started the program of liberalization of prices in the setting of the general economic reforms that has been putted along the period. While, 1987-1990 has been characterized by a period of stabilization of inflation rate around an average of $7.4 \%$. This result is attributable to a politics of management of the interior demand based on a compression of the public expenses to the bending of the inflation level. The period 1991-1994 distinguishes itself by a decrease of the inflation rate around $5.7 \%$ on average per year this decrease is the result of the pursuit of the restraining budgetary and monetary policies. From the second half of the year 1994 to pass to $6.3 \%$ in 1995 this evolution resulted from the circumstantial factors, as the increase in prices world for imported most products, and the decrease of the prices of some agricultural products (Study economic of the World Bank on Middle East and North Africa (1996, pp: 1 -5)). The period 1996-2002 knew an important deceleration of the inflation rate, which was located between - 1.7\% in 1996 and $2.8 \%$ in 2002 .

This reduction of the inflation observed these last years contributed to creates a favorable and stimulating climate for the private investments and permitted to reduce the interest rates, encouraging the dynamic of the economic activity, the creations of jobs and exports thus (Report of the central bank 2000, pp: 97-101)). Using a Markov-switching approach, two main regimes for inflation in Tunisia was identified over the period 2001-2009: a low and stable inflation regime associated with a low pass-through level, and a high inflation regime associated with a high pass-through level. Their empirical results show that industrial production index and the imports have a high pass-through level. However, exports increase the probability to stay in a low inflation regime and a low pass-through level. Figure 2 displays the evolution of the inflation during the last two decades for Tunisia.

However, the inflation, during 2009-2010, increased slightly and slowly while remaining moderate. Indeed, the inflation measured by the total IPC (average of the period) was 3.7\% in 2009 and increased 


\section{Inflation (IPC)}

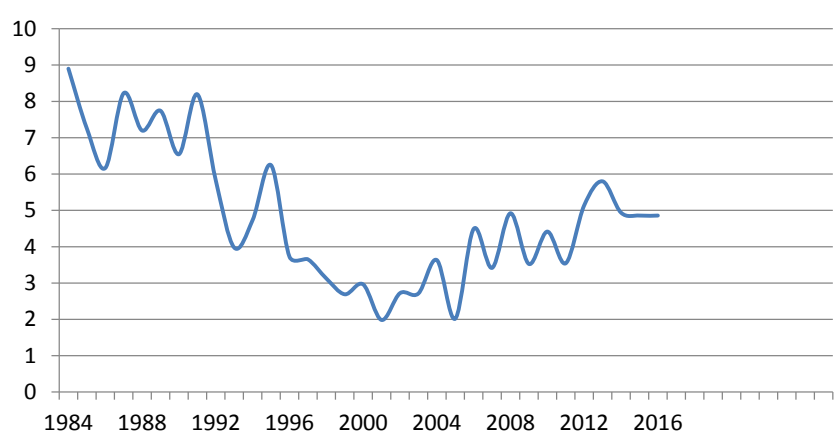

Figure 2: The evolution of the inflation (1984-2016)

to $4.5 \%$ in May 2010 . This increase is largely due to the growth of the prices of the food products.

The annual average inflation rate reached $5.6 \%$ in 2012, as compared to $3.5 \%$ in 2011 , primarily in connection with the rise in prices across all product groups, in particular foodstuffs, whose prices had risen by $8.4 \%$ by the end of the preceding year. In particular, since June 2012, inflationary pressure has become inertial. This inflation increase can also be due to the progression of internal demand. The output gap ${ }^{9}$ was negative in the post-revolutionary period, going from +1.82 in 2010 to -2.31 in 2011 and -1.95 in 2012 . Nonetheless, there was an increase of 0.36 points between 2011 and the third quarter of 2012 (year on year), which means an overall upward trend in aggregate demand. In addition, the pass-through effects associated with inflation imported through effective nominal explain depreciation of the exchange rate. Nevertheless, the BCT has made undeniable efforts to support the exchange rate through intervention in the foreign exchange market to adjust the inflation differential relative to partners.

After ending its policy of full liquidity allocation in 2011, the CBT continued in 2013 with a policy initiated in 2012 based on a neutral intervention strategy in line with the evolution of autonomous liquidity factors. This direction is justified by the fact that inflation is not based solely on monetary factors in Tunisia. In December 2013, the CBT decided to introduce swap accords as a new monetary policy tool in order to broaden its range of tools for regulating bank liquidity and better steer the interbank interest rate. The CBT intends in this way to reinforce the efficiency of its monetary policy in terms of price stability. Inflation was fed notably by increased food prices, the depreciation of the dinar against the euro and contraband and insufficient control of distribution circuits ${ }^{10}$. In 2014, the inflation rate reaches $5.5 \%$ and declines to $4.9 \%$ in 2015 . The study ${ }^{11}$ concluded that the administered prices constitute a major obstacle to measure, interpret and forecast inflation. In fact, the CBT has no control over 30\% of the CPI basket. This is a sign of weakness of the economic system and the need for monetary authorities to continue its efforts to liberalize prices. We can conclude that inflation in Tunisia is increasing in recent years for various reasons (lack of supply, continued depreciation of the dinar, the current account deficit ...). This is damning the purchasing power

9i.e., The gap between production and potential production.

${ }^{10}$ see African Economic Outlook 2014

${ }^{11}$ GhrissiMhamdi, MounirSmida, RamziFarhani. Indicators of core inflation: Case of Tunisia. interdisciplinary journal of contemporary research in business, 2014 pp.interdisciplinary journal of contemporary research in business. of Tunisians. The transition to a more flexible monetary regime which is IT remains a challenge in itself. In fact, the CBT became more transparent towards the public and more or less independent from political power and there are great efforts being made within the CBT in order to establish an inflation analysis and forecasting in the short and medium terms. But, this is not sufficient since IT requires restructuring and adjustments at all levels.

\section{Data and Method Specification}

Some empirical studies explained the relationship between the exchange rate and inflation by a simple regression equation. We will proceed as who used the VAR approach to analyze the unidirectional or bidirectional relationship between the real effective exchange rate ${ }^{12}$ and inflation rate, measured by the average consumer price in Tunisia. Our data are out of IMF statistics for the period (1984-2016).

The empirical study is based on annual observations. We applied the vector autoregressive (VAR) model to examine the relationship between inflation and real effective exchange rate. This technique was popularized by Sims (1980). The VAR model was developed in the macroeconomics literature as an attempt to characterize the joint time-series of a set (vector) of variables without making the restrictive (and perhaps false) assumptions that would allow the identification of structural dynamic models. It provides a multivariate framework where changes in a particular variable are related to changes in its own lags and the lags of other variables. This is a reduced-form of VAR since the dependent variable is expressed in terms of predetermined lagged variables [10]. The advantage of VAR approach is that unknown relationships between variables are considered as endogenous in the system as the variables relationship is simultaneously determined. The VAR model could be simplified as follows:

$$
\mathrm{Yt}=\beta+\mathrm{A} 1 \mathrm{Yt}+\ldots \mathrm{Ap} \mathrm{Ytp}-1+\mathrm{BZt}+\varepsilon \mathrm{t}
$$

Where (Yt) is a vector of endogenous variables, $(\beta)$ is an intercept, $(\mathrm{Z})$ is a vector of exogenous variables, (A ) and (B) are coefficient matrices, $(p)$ is the lag length and ( $(\mathrm{t})$ is an unobservable zero-mean white noise (Table 1 ).

These results show that the mean inflation is around $5 \%$ with a minimum of $1.9 \%$ in 2001 and a maximum of $8.9 \%$ a very high value attempted in 1984. We see that the exchange rate is on average around 1.2 and attempted a minimum value of 0.77 in 1984 and a maximum of 1.9 attempted in 2015 and 2016. The analysis of the evolution of inflation before and after the Tunisian revolution reveals that between 1984 and 2010 inflation averaged $4.8 \%$, it declined in 2011, year of the Tunisian revolution reaching $3.5 \%$, rose to $5.13 \%$ in 2012 and slightly decreased to reach $4.8 \%$ during the period 2013-2015. This was explained by the NIS and $\mathrm{CBT}^{13}$ by the price increase of the food and beverages group ${ }^{14}$. Turning to the exchange rate, the average value is about 1.1 during the pre-revolutionary period. In 2011 , it attempted 1.4 but it kept nearly the values of 2010 and 2009. After the Tunisian revolution, the national currency has dramatically evolved to reach.

\begin{tabular}{|l|l|l|l|l|l|}
\hline Variable & Obs & Mean & Std. Dev & Min & Max \\
\hline Inflation & 33 & 4.852173 & 1.891221 & 1.983333 & 8.9 \\
\hline Exchange Rate & 33 & 1.212054 & 0.32065 & 0.7768334 & 1.961625 \\
\hline \multicolumn{5}{r}{ Table 1: Summary statistics. } \\
\end{tabular}

${ }^{12}$ With $(2010=100)$

${ }^{13}$ National Institute of Statistic (NIS)

${ }^{14}$ This is due to a strong increase in prices of fruit and dried fruits of $11,1 \%$, edible oils, fish and vegetables by $9 \%, 8.4 \%$ and $5.4 \%$ respectively. 
Before starting a VAR estimation model, it is crucial to test for the stationarity of the time series data. Unit root tests are generally employed in order to identify the variables that belong to a stationary series. This is particularly essential as the stationarity of macroeconomic series are limited in general. For this purpose we used ${ }^{15}$ stationarity test. Under the unit root null hypothesis the variables have a unit root. Autoregressive unit root tests are based on testing the null hypothesis that $\varphi=1$ (difference stationary) against the alternative hypothesis that $\varphi<1$ (trend stationary). They are called unit root tests because under the null hypothesis the autoregressive polynomial of $\mathrm{zt}, \varphi(\mathrm{z})=(1-\varphi \mathrm{z})=0$, has a root equal to unity. Stationarity tests take the null hypothesis that yt is trend stationary.

To test the unit root hypothesis, the following regressions of the ADF test and Phillips-Perron tests (PP) were utilized:

ADF test regression: $\Delta \mathrm{x}_{\mathrm{t}}=(\mathrm{p}-1) \mathrm{x}_{\mathrm{t}-1}+\sum_{\mathrm{i}}^{\mathrm{n}} \varphi_{\mathrm{i}} \Delta \mathrm{x}_{\mathrm{t}}-1+\mathrm{u}_{\mathrm{r}}$

Phillips - perron test regression : $\Delta \mathrm{x}_{\mathrm{t}}=\beta^{\prime} \mathrm{D}_{\mathrm{t}}+\pi \mathrm{x}_{\mathrm{t}-1}+\mathrm{u}_{\mathrm{t}}$

We conduct these two different unit root tests ${ }^{16}$, and the ADF and PP tests suggest stationarity at the $1 \%$ significance level. Consequently, it was assumed that all the time series are stationary after one differentiation. The results in the table show that for all variables, we cannot reject the unit root test (Table $2 \mathrm{a}$ and $2 \mathrm{~b}$ ).

Following these results, we can run the Johansen tests for cointegration. Testing for the order of integration is standard in applied econometric work. The Johansen tests are called the maximum eigenvalue test and the trace test. To test for the existence of Cointegration using the trace test, we set $\mathrm{K} 0=0$ (no cointegration), and

\begin{tabular}{|c|c|c|c|c|c|c|}
\hline \multirow[t]{2}{*}{ Variables } & \multicolumn{3}{|c|}{ Levels } & \multicolumn{3}{|c|}{$1^{\text {st }}$ Difference } \\
\hline & & (ii) & (iii) & (i) & (ii) & (iii) \\
\hline Inflation & -1.457 & -2.596 & $-2.761^{* * *}$ & $-9.264^{* * *}$ & $-9.379^{* * *}$ & $-9.195^{* * *}$ \\
\hline Exchange Rate & 2.630 & -1.381 & 0.628 & $-4.489^{* * *}$ & $-5.373^{* * *}$ & $-5.153^{* * *}$ \\
\hline
\end{tabular}

(i): Without intercept; (ii): with an intercept, and (iii): with an intercept and trend.

${ }^{* * *}$ mean a $p$-value less than $1 \%$.

Critical levels in the model: (i), $-2.649,(1 \%),-1.950,(5 \%),-1.603,(10 \%)(i i),-4.316,(1 \%),-3.572,(5 \%),-3.223,(10 \%),(i i i),-2.457,(1 \%),-1.697,(5 \%),-1.310,(10 \%)$. Table 2a: Unit root test (augmented dickey-fuller test).

\begin{tabular}{|l|c|c|c|c|}
\hline Variables & \multicolumn{2}{|c|}{ Level } & \multicolumn{2}{|c|}{$1^{\text {st }}$ difference } \\
\hline & (i) & (ii) & (ii) & $-41.825^{\star * *}$ \\
\hline Inflation & -1.454 & -9.950 & $-41.205^{\star * *}$ & $-25.596^{\star * *}$ \\
\hline Exchange Rate & 1.006 & -7.208 & $-30.335^{\star * *}$ & \\
\hline
\end{tabular}

(i): Without intercept (ii) : with Trend.

${ }^{* * *}$ mean a $p$-value less than $1 \%$.

Critical levels in the model: (i) (1\%), -12.180, (5\%), -7.412, (10\%), -5.356, (ii) (1\%) -23.396, (5\%), -18.432, (10\%), -15.936.

Table 2b: Unit root test (phillips-perron test).

\begin{tabular}{|c|c|c|c|c|c|}
\hline \multicolumn{4}{|c|}{ Trend: Constant } & \multicolumn{2}{c|}{ Number of obs=31 } \\
\hline \multicolumn{3}{|c|}{ Sample: 1986-2016 } & \multicolumn{2}{c|}{ Lags=2 } \\
\hline Maximum Rank & Parms & LL & Eigenvalue & Trace Statistic & Critical value \\
\hline 0 & 6 & -12.326338 & - & 6.7372 \\
\hline 1 & 9 & -9.8234491 & 0.14911 & 1.7314 \\
\hline 2 & 10 & -8.9577585 & 0.05432 & - \\
\hline
\end{tabular}

Table 3: Johansen tests for cointegration.

${ }^{15}$ Phillips, P. C. B.; Perron, P. (1988)."Testing for a Unit Root in Time Series Regression". Biometrika. 75 (2): 335-346. doi:10.1093/biomet/75.2.335.

${ }^{16}$ The (PP) differ from the Dickey-Fuller (ADF) tests of mainly in how they deal with serial correlation and heteroskedasticity in the errors. In particular, where the Dickey-Fuller ADF tests use a parametric autoregressive to approximate the ARMA structure of the errors in the test regression, the Phillips-Perron tests ignore any serial correlation in the test regression. exchange rate volatility than in non-IT countries. This suggests that exchange rate volatility under IT countries with "managed" regimes tend to be lower than those with flexible regimes.

As our results confirm that the inflation rate variations are followed

${ }^{17}$ Www.investopedia.com 


\begin{tabular}{|c|c|c|c|c|c|c|c|c|}
\hline \multicolumn{5}{|c|}{ Sample: 1988-2016 } & \multicolumn{4}{|c|}{ Number of obs $=29$} \\
\hline Lag & LL & LR & Df & $\mathbf{P}$ & FPE & AIC & HQIC & SBIC \\
\hline 0 & -59.253 & & & & 0.234253 & 4.22435 & 4.25388 & 4.31864 \\
\hline 1 & -13.3763 & 91.754 & 4 & 0 & 0.013063 & 1.33629 & 1.42489 & 1.61918 \\
\hline 2 & -6.25862 & 14.235 & 4 & 0.007 & .010594 & 1.12128 & 1.26895 & 1.59277 \\
\hline 3 & -5.14939 & 2.2185 & 4 & 0.696 & 0.013093 & 1.32065 & 1.52737 & 1.98072 \\
\hline 4 & -2.91051 & 4.4778 & 4 & 0.345 & 0.015126 & 1.4421 & 1.7079 & 2.29077 \\
\hline
\end{tabular}

Table 4: Selection-order criteria.

\begin{tabular}{|c|c|c|c|c|c|c|c|}
\hline \multirow{2}{*}{ Inflation } & & \multirow[t]{2}{*}{ Coefficient } & \multirow[t]{2}{*}{ Std. error } & \multirow[t]{2}{*}{$\mathbf{z}$} & \multirow[t]{2}{*}{$P>|z|$} & \multicolumn{2}{|c|}{ (95\% Conf. Interval) } \\
\hline & & & & & & & \\
\hline & Inflation & & & & & & \\
\hline & L1. & $0.3997838^{\star *}$ & 0.1627743 & 2.46 & 0.014 & 0.0807521 & 0.7188155 \\
\hline & L2. & $0.4253781^{* * *}$ & 0.1613102 & 2.64 & 0.008 & 0.1092159 & 0.7415403 \\
\hline \multicolumn{8}{|l|}{ Exchange } \\
\hline & L1. & -1.277009 & 2.341394 & -0.55 & 0.585 & -5.866057 & 3.312038 \\
\hline & L2. & 1.838487 & 2.684341 & 0.68 & 0.493 & -3.422725 & 7.099699 \\
\hline & Cons & 0.0881013 & 1.601957 & 0.05 & 0.956 & -3.051677 & 3.22788 \\
\hline \multicolumn{8}{|l|}{ Exchange } \\
\hline & Inflation & & & & & & \\
\hline & L1. & -0.0172763 & 0.0116642 & -1.48 & 0.139 & -0.0401377 & 0.005585 \\
\hline & L2. & $0.0268783^{* *}$ & 0.0115592 & 2.33 & 0.02 & 0.0042226 & 0.0495339 \\
\hline \multicolumn{8}{|c|}{ Exchange Rate } \\
\hline & L1. & $1.002321^{* \star *}$ & 0.1677807 & 5.97 & 0 & 0.6734767 & 1.331165 \\
\hline & L2. & 0.098027 & 0.1923557 & 0.51 & 0.61 & -0.2789833 & 0.4750373 \\
\hline & cons & -0.1293439 & 0.1147938 & -1.13 & 0.26 & -0.3543356 & 0.0956478 \\
\hline
\end{tabular}

${ }^{* * *},{ }^{* *}$ significant at $1 \%$ and $5 \%$.

Table 5: VAR model results.

by significant exchange rate impact responses. The positive and significant coefficient of inflation exchange rate suggest that increased inflation cause increased demand for domestic currency leading to its appreciation.

It was concluded that the phenomenon of volatility rising with IT regimes is mainly due to floating exchange rate regimes since the result is overturned after controlling for exchange rate regimes. The explore of this issue and finds that IT regimes tend to have lower exchange rate volatility. In a credible inflation target regime, argue that positive (negative) inflation surprises trigger increases (reductions) in short-term domestic interest rates leading to increased (reduced) real returns on the domestic currency. These, in turn, cause increased (reduced) demand for domestic currency leading to its appreciation (depreciation). This response goes against the predictions of the textbook Purchasing Power Parity (PPP) hypothesis under which increasing (decreasing) inflation rates cause currency depreciation (appreciation). It appears paradoxical but it can be explained by the inflation-targeting monetary policy. According to the regimes seem to have experienced greater real effective exchange regime volatility, largely driven by external prices in developed countries. For developing countries, IT regimes show no difference in REER ${ }^{18}$ volatility, though there is some evidence that they have lower volatility in internal prices.

So, the relationship between the inflation rate and the exchange rate regime is non-monotone. In fact, this relationship is based on monetary policy considerations and, in particular, asymmetric monetary policy preferences (Table 5).

${ }^{18}$ The real effective exchange rate (REER) is the weighted average of a country's currency relative to an index or basket of other major currencies, adjusted for the effects of inflation. The weights are determined by comparing the relative trade balance of a country's currency against each country within the index. This exchange rate is used to determine an individual country's currency value relative to the other major currencies in the index, such as the U.S. dollar, Japanese yen and the euro.
The Angle and Granger causality test showed that if the series $\mathrm{X}$ and $\mathrm{Y}$ are individually $\mathrm{I}(1)$ then there would be a causal relationship at least in one direction. Granger-causality test detects the causal relationship between two or more variables. A time series is said to Granger-cause another time series if the prediction error of current $\mathrm{Y}$ declines by using past values of $\mathrm{X}$ in addition to past values of $\mathrm{Y}$. We apply a standard Granger causality test looking at whether there is any causal relation between the inflation and the exchange rate. The Granger causality tests in Table 6 highlighted the causal relationship between the two variables. In fact, the feedback hypothesis is confirmed for Tunisia, showing that there is unidirectional causality between the inflation and the exchange rate. Results show that there is a unidirectional relationship running from inflation to the exchange rate. This result is important for the policy makers in Tunisia and the government, because it has not set any specific targets for the exchange rate. The exchange rate changes become relevant for monetary policy only if they influence inflation for Tunisia.

Then, we test the hypothesis that all coefficients except the constant term are zero. The results show a significant P-value. So, we can reject the null hypothesis and all coefficients in the specification are not nulls. Next, we implement a Lagrange multiplier (LM) test for autocorrelation in the residuals of VAR model, which was resented ${ }^{19}$. The test is performed at lags $j=2$. In our case, the null hypothesis of the test is that there is no autocorrelation at lag 2 (Table 7). For each variable, we present a test for normality based on Jarque-Bera, skewness and kurtosis tests. The p-values shown in the table above indicate that we can accept the null hypothesis indicating that residuals are normally distributed (Table 8).

\section{Concluding Remarks and Policy Implications}

Our paper studies the probable existence of causality links between

${ }^{19}$ Johansen S, 1995, Likelihood-Based Inference in Cointegrated Vector Autoregressive Models (New York: Oxford University Press). 
Citation: Loukil S (2017) Economic Challenges and Opportunities after the Revolution in Tunisia: Inflation and Exchange Rate. J Glob Econ 5: 260. doi: $10.4172 / 2375-4389.1000260$

Page 7 of 7

\begin{tabular}{|c|c|c|c|c|}
\hline Equation & Excluded & chi $^{\mathbf{2}}$ & df & Prob> $\mathbf{c h i}^{\mathbf{2}}$ \\
\hline Inflation & Change rate & 0.54684 & 2 & 0.761 \\
\hline Inflation & All & 0.54684 & 2 & 0.761 \\
\hline Exchange & Inflation & 5.4073 & 2 & 0.067 \\
\hline Exchange & All & 5.4073 & 2 & 0.067 \\
\hline
\end{tabular}

Table 6: VAR granger causality/Block erogeneity wald tests.

\begin{tabular}{|l|l|l|l|}
\hline \multicolumn{2}{|l|}{ Lagrange-multiplier test } & & \\
\hline Lag & chi $^{2}$ & df & Prob> chi \\
\hline 1 & 4.3672 & 4 & 0.35859 \\
\hline 2 & 4.8797 & 4 & 0.29987 \\
\hline
\end{tabular}

Table 7: Lagrange-multiplier test for residual autocorrelation.

\begin{tabular}{|c|c|c|c|c|}
\hline \multicolumn{5}{|c|}{ Jarque-Bera test } \\
\hline Equation & chi $^{2}$ & df & Prob>chi & \\
\hline Inflation & 0.112 & 2 & 0.94552 & \\
\hline Exchange & 0.162 & 2 & 0.92217 & \\
\hline All & 0.274 & 4 & 0.99142 & \\
\hline \multicolumn{5}{|c|}{ Skewness test } \\
\hline Equation & Skewness & chi $^{2}$ & df & Prob> chi \\
\hline Inflation & 0.08841 & 0.04 & 1 & 0.84073 \\
\hline Exchange & 0.11222 & 0.065 & 1 & 0.79865 \\
\hline All & \multicolumn{5}{|c|}{ Kurtosis test } \\
\hline Equation & Kurtosis & chi $^{2}$ & df & Prob> chi \\
\hline Inflation & 2.7645 & 0.072 & 1 & 0.78894 \\
\hline Exchange & 2.726 & 0.097 & 1 & 0.75547 \\
\hline All & \multicolumn{5}{|c|}{0.169} & 2 & 0.91913 \\
\hline
\end{tabular}

Table 8: Tests for normality.

the exchange rate and the inflation in Tunisia. First, we clarified the Tunisian monetary strategy. Then, we study the relationship between inflation and exchange rate. The empirical results show that exchange rate does not affect the inflation rate suggesting that the pass-through rate is very low. This link can be more developed through the study of the likely effects of previous lagged values of exchange rate. Moreover, the inflationary environment (at 10\% of significance level) is more frequently observed to Granger cause the exchange rate. These results imply some help for economic policy-makers in Tunisia in their quest for inflation, exchange rate and stability. A policy of inflation targeting, as an alternative monetary policy, combined with a compatible regime of flexible exchange rates could provide a solution to this dilemma. In fact, with a constant real exchange rate rule, an inflation targeting regime will not be sufficient to properly contain the inflation pressures caused by demand shocks. So, coordinated efforts are needed from central bank policy makers in order to avoid sending mixed signals to economic agents about its monetary policy stance which endanger the achievement of its inflation target and have adverse effects on the exchange rate and the policy stability.

\section{References}

1. Amuzegar, Jahangir (1992) The Iranian economy before and after the revolution. Middle East Journal 46: 413-425.

2. Achy L (2011) Tunisia's economic challenges. Washington, DC: Carnegie Endowment for International Peace, pp: 1-28.

3. Hakimian H, Karshenas M. (2000) Dilemmas and prospects for economic reform and reconstruction in Iran. The Economy of Iran: Dilemmas of an Islamic State, pp: 29-62.

4. Richards A (1993) Economic imperatives and political systems. Middle East Journal 47: 217-227.

5. Esfahani HS, Pesaran MH (2009) The Iranian economy in the twentieth century: A global perspective. Iranian Studies 42: 177-211.

6. Amuzegar J (1999) Khatami and the Iranian economy at mid-term. The Middle East Journal. 53: 534-552.

7. Henry CM, Robert S (2010) Globalization and the Politics of Development in the Middle East. Cambridge University Press.

8. Amin M, Assaad R, al-Baharna N, Dervis K, Desai RM, et al. (2012) After the spring: Economic transitions in the Arab world. Oxford University Press.

9. Bhuiyan SI (2011) Social media and its effectiveness in the political reform movement in Egypt. Middle East Media Educator 1: 14-20.

10. Maher S (2011) The political economy of the Egyptian uprising. Monthly Review 63: 1-32. 